\title{
Commetáa
}

\section{Educação de surdos na Espanha: análise bibliométrica em bases de dados de teses doutorais (1987-2017)}

\author{
Daiane Natalia Schiavon \\ Doutora; Universidade Federal de São Carlos, São Carlos, SP, Brasil; \\ daia_schiavon@yahoo.com.br \\ Maria Cristina Piumbato Innocentini Hayashi \\ Doutora; Universidade Federal de São Carlos, São Carlos, SP, Brasil; \\ dmch@ufscar.br
}

\begin{abstract}
Resumo: A educação de alunos surdos é um tema presente em debates acadêmicos refletindo-se em estudos no cenário da produção científica nacional e internacional. O objetivo do presente trabalho é identificar e analisar a produção científica espanhola oriunda de teses doutorais sobre a educação de surdos e apresentar indicadores bibliométricos que melhor representem o perfil das temáticas destas pesquisas. De abordagem bibliométrica combinada com a análise de conteúdo, o estudo elegeu para seleção das teses a Base de Datos de Teses Doctorales e a base Tesis Doctorales en Rede, ambas do Ministerio de Educación, Cultura y Deporte do Gobierno de España, mediante a utilização das seguintes expressões de busca "sordos", "sordera", "deficiencia auditiva" e "discapacidad auditiva". As seguintes categorias foram analisadas no corpus selecionado $(\mathrm{n}=45)$ : evolução temporal, autores, orientadores e seus respectivos gêneros, instituições de defesa, áreas de conhecimento, temáticas e abordagens comunicativas utilizadas nos estudos. Os resultados desse panorama bibliométrico expressam uma diversificada produção científica sobre educação de surdos em programas de doutorado $(n=28)$ em universidades espanholas $(\mathrm{n}=22)$ sobre diferentes temáticas, entre as quais aquelas relacionadas à população alvo dos estudos e às biotecnologias assistivas, com preponderância de estudos nas áreas de Educação, Psicologia e Linguística. Verificou-se que dentre as abordagens comunicativas adotadas nos estudos preponderou o oralismo e o bilinguismo. Nas conclusões recomenda-se que futuros estudos utilizem diferentes bases de dados e tipologias documentais, tais como artigos científicos, visando estabelecer comparações e ampliar as análises sobre a produção científica de educação de surdos.
\end{abstract}

Palavras-chave: Educação de surdos. Espanha. Produção científica. Bibliometria.

\section{Introdução}

A educação de alunos surdos é um tema que tem promovido inúmeras discussões no contexto acadêmico gerando diversos estudos que visam identificar os inúmeros aspectos envolvidos nas políticas de inclusão de pessoas 
com deficiência auditiva no ambiente escolar. Por consequência, essa temática reflete-se na produção científica nacional e internacional consolidada em trabalhos acadêmicos de mestrado e doutorado e em artigos de periódicos., a partir de abordagens de diversas áreas de conhecimento, como por exemplo a Educação Especial, a Linguística, e a Psicologia.

A motivação do presente estudo advém de pesquisas anteriores das autoras sobre a inclusão de alunos surdos tanto no contexto brasileiro (RAMOS; HAYASHI, 2018) quanto no cenário espanhol (SCHIAVON, 2017; SCHIAVON; HEREDERO, 2018). Pesquisas como essas, oriundas da análise de trabalhos acadêmicos, possibilitam identificar possíveis tendências, perspectivas e lacunas existentes, com vistas a fornecer subsídios a investigações futuras, além de contribuir para o aprimoramento desse campo de investigação.

Com relação à Educação Especial, a Espanha é um dos países precursores os pressupostos e princípios da escola inclusiva, acumulando certa experiência na dinâmica desse processo e assimilação dos novos conceitos e desafios impostos pelos paradigmas de uma nova dimensão frente à escola. E a Espanha tornou-se também pioneira na educação de surdos, considerada "berço" das iniciativas educacionais com estes indivíduos por meio do professor e Frei Beneditino Pedro Ponce de León - o mesmo ensinou a falar, vários surdos de nascimento, filhos de aristocratas ricos que tinham recursos para confidenciarlhes estes tutorados (GASCÓN; STORCH, 2004). De acordo com Tiana Ferrer (2004), a Espanha tem alcançado um nível expressivo de desenvolvimento, que tem afetado os diversos aspectos da vida social, política, econômica e cultural daquela sociedade, e que consequentemente influenciam na produção científica das mais distintas áreas e, neste tocante, à educação de surdos.

Esse cenário suscita a importância de se empreender análises e revisões críticas sobre a produção científica espanhola, de modo a delinear um panorama sobre o estado do conhecimento sobre a educação de surdos nesse país. Assim, no presente estudo partimos das seguintes questões de pesquisa: $\mathrm{O}$ que indica a produção científica espanhola sobre a educação de surdos? O que aponta esta produção quanto à predominância de uma ou outra modalidade comunicativa? 
Assim, configura-se como objetivo geral do presente estudo: identificar e analisar a produção científica espanhola sobre a educação de surdos oriunda de pesquisas acadêmicas de doutorado disponíveis em bases de dados de teses doutorais defendidas em Universidades espanholas e indicar os parâmetros bibliométricos que melhor representem as temáticas destas pesquisas.

\section{Método}

Considerando a problemática e os objetivos do presente estudo foram adotadas abordagens qualitativa e quantitativa, com o intuito de fomentar respostas mais aprofundadas do fenômeno estudado, uma vez que ambas são complementares, ou seja, não existe contradição entre uma e outra (MINAYO; SANCHEZ,1993; SILVA; HAYASHI; HAYASHI, 2011).

Desse ponto de vista, a metodologia adotada combinou a análise de conteúdo com a análise bibliométrica. A primeira, consiste em um conjunto de técnicas utilizadas para realizar descrições objetivas e sistemáticas de mensagens enunciadas permitindo a inferência de conhecimentos extraídos dos textos analisados (JANIS, 1982). A segunda, permite o mapeamento da literatura científica de determinada área de conhecimento e os resultados são evidenciados por meio da construção de indicadores da produção científica e tecnológica de autores, grupos, instituições e países (VAN RAAN, 2004).

Ainda, é válido afirmar que a bibliometria tem sido utilizada em diversos estudos para analisar a produção científica sobre várias temáticas relacionadas à surdez, tais como: a educação de surdos (KING, 1989; RAMOS; HAYASHI, 2018); a língua de sinais (ARIK, 2014; SANTOS; OLIVEIRA, 2017); a interpretação de língua de sinais (ALBRES; LACERDA, 2013); os surdos e a surdez (SILVA; SANTOS; RODRIGUES, 2011).

Elegeram-se como fontes de informação dessa pesquisa as seguintes bases de dados: Base de Datos de Tesis Doctorales, TESEO (ESPAÑA, 2018) e Tesis Doctorales en Red, TRD (2018) - Base de Dados de Teses Doutorais e Teses Doutorais em Rede, respectivamente. A Base TESEO é um sistema de informação online vinculado ao Ministério de Educação da Espanha que reúne informações de teses defendidas em universidades espanholas desde 1976. A Base TRD é um repositório cooperativo que reúne atualmente 28.853 teses 
defendidas em quinze universidades espanholas com ênfase para as universidades da Catalunha e de outras comunidades autônomas desde 1971.

$\mathrm{Na}$ Espanha o ensino superior é formado por Grado, Máster y Doctorado. O termo Grado refere-se à titulação a nível superior. Já o Máster, se divide em duas subcategorias: universitarios/oficiales - regulamentados pela Agencia Nacional de Evaluación de la Calidad y Acreditación (ANECA), órgão que tem por objetivo avaliar e certificar as Instituições - e propios/profesionales, que são oferecidos por entidades privadas e não são regulamentados pela ANECA, por isso, não possuem validade fora do território espanhol. O Máster é obrigatório para cursar o Doctorado. O Doctorado é o último e mais importante grau acadêmico que é conferido por uma universidade ou outra instituição autorizada para isso (ESPAÑA, 2008).

Optou-se por investigar as teses doutorais pois como argumentam Fernández-Cano, Torralbo e Vallejo (2012) esses trabalhos de pós-graduação são uma rica e valiosa fonte de dados que refletem as conquistas de uma disciplina científica, de um sistema nacional de pesquisa e de pesquisadores individuais. Como tal, as teses doutorais também se constituem em indicadores cientométricos, conforme salientam Sanz-Casado, de Filippo, García Zorita e Efraín-García (2011), pois permitem conhecer a capacidade de formar pessoal para as atividades de pesquisa nas universidades. Ademais, conforme enfatiza o estudo sobre teses espanholas de Sánchez-Jiménez, Blázquez Orlando, Montesi e Botezan (2017), muitas pesquisas de doutorado têm sido associadas ao aumento da publicação de artigos incluídos nas bases de dados Web of Science (WoS) e Scopus.

A coleta de dados nas bases de teses doutorais TESEO e TDR ocorreu em março de 2018 e foram utilizadas expressões de busca em língua espanhola retiradas da literatura científica, a saber: "sordos", "sordera", "deficiencia auditiva" e "discapacidade auditiva". Foi utilizado o recurso "busca avançada", delimitando as expressões selecionadas aos campos "título", "resumén" $e$ "palabras-clave" sem delimitação temporal, visando recuperar todas as teses doutorais sobre a temática disponíveis nas bases selecionadas.

Do total de registros recuperados em ambas as bases $(n=160)$ - sendo 51,2\% ( $\mathrm{n}=82)$ na base TESEO e 48,2\% (n=78) na base TDR - foram excluídos 
os repetidos $(n=77)$ e aqueles que não se enquadravam ao escopo da pesquisa $(\mathrm{n}=38)$, pois se referiam às áreas da História e da Medicina, abordando aspectos históricos e médicos da surdez. Configurado o corpus final da pesquisa $(n=45)$ verificou-se que deste total $42,2 \%(n=19)$ só possuíam resumo restando $57,8 \%$ ( $n=26)$ com texto completo disponível.

Na sequência, os dados foram organizados em uma planilha utilizando o software MS Excel e sistematizados mediante parâmetros bibliométricos (evolução temporal, autores e orientadores, gênero, instituições de defesa, áreas de conhecimento, palavras-chave) e de conteúdo (temáticas dos trabalhos e abordagens comunicativas abordadas nos estudos). Na sequência foram elaborados indicadores quantitativos representados por gráficos e tabela. Por fim, os dados foram analisados e interpretados à luz do referencial teórico do estudo sinalizando possíveis tendências, perspectivas e lacunas existentes na literatura científica sobre educação de surdos oriunda de teses doutorais espanholas.

\section{Resultados e discussão}

A Figura 1 exibe a distribuição temporal das teses doutorais cobrindo um período compreendido entre 1987 e 2017, sendo que foi constatada ausência de teses doutorais sobre a temática pesquisada nos anos de 1989 e 1990, 1992, 1998 e 1999, e em 2002.

Figura1 - Distribuição temporal das teses

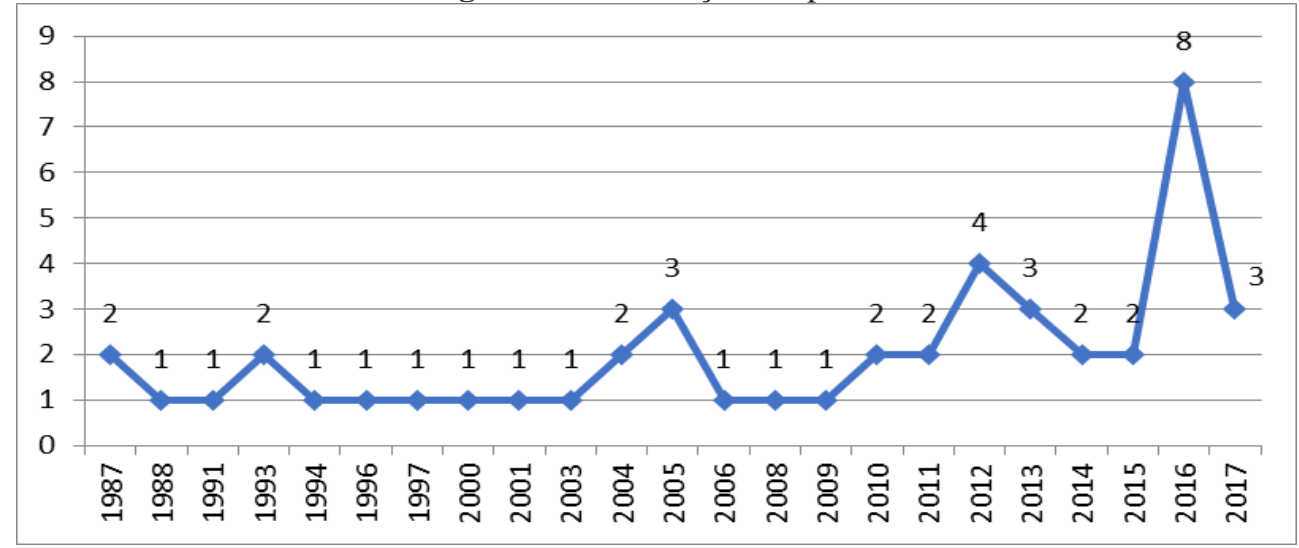

Fonte: Elaboração das autoras. 
Nota-se na Figura 1 que duas teses foram defendidas em 1987 delimitando assim esse ano como sendo o de início da produção acadêmica relacionada ao tema estudado. Pode-se inferir que a produção de tais teses ocorreu devido ao momento histórico que atravessava esta sociedade, quando na Espanha havia se consolidado em termos legais um novo modelo de educação especial, isto é, o mesmo adquiriu caráter normativo por meio do Real Decreto 334/1985, de Ordenación de la Educación Especial, o qual estabelece o propósito de "integrar a los niños com discapacidad en los centros ordinários públicos y concertados" (ESPAÑA, 1985, p. 6.917), além de contemplar a formação profissional e proporcionar apoios necessários e atenção personalizada, regulamentando-se como parte integrante do sistema educativo e não mais como modalidade educativa, dirigindo-se a pessoas afetadas por diminuições físicas, psíquicas ou sensoriais (GONZÁLEZ PÉREZ, 2009). Neste sentido, a integração de alunos com deficiência nas classes comuns iniciou-se a partir da Ordem de 20 de março de 1985, por meio do planejamento da educação especial e da integração no curso de 1985 e 1986, bem como com a criação do Centro Nacional de Recursos para a Educação Especial (ESPAÑA, 1985).

A média de trabalhos $(n=1,9)$ de modo geral é uniforme, com ligeiros aumentos nos totais relativos aos anos de $2005(n=3)$ e $2012(n=4)$, e expressivo acréscimo em $2016(n=8)$, voltando ao patamar anterior em $2017(n=3)$. Nota-se uma concentração das pesquisas entre os anos de 2008 e 2012 (n=9), período este posterior ao reconhecimento legal da Lengua de Signos Española (LSE) dada pela Lei 27/2007, que reconheceu as línguas de sinais espanholas e regulamentou os meios de apoio à comunicação oral às pessoas surdas (ESPAÑA, 2007). Essa expansão sugere um impacto positivo da legislação para o desenvolvimento da área.

Nos anos de 2013 e 2016 entraram em vigor a Ley Orgánica para la Mejora de la Calidad Educativa 8/2013 (LOMCE), de 9 de dezembro de 2013, que introduz 109 modificações na lei anterior de 2006, a Ley Orgánica de Educación (LOE). As principais mudanças relacionaram-se à definição e elementos do currículo, tipos de disciplinas e avaliações externas com todos os alunos, dentre eles, o "alumnado con necesidad específica de apoyo educativo" - ACNEAE (ESPAÑA, 2013). Essa nova legislação fez com que um maior 
número de pesquisadores centrasse seus olhares para esses alunos e sua escolarização refletindo no aumento gradativo de publicações nessa área. Os achados da pesquisa confirmam esse incremento da produção científica entre 2013 e 2017 (n=18) que é 50\% superior ao encontrado no período entre 2008 e $2012(n=9)$.

Verificou-se ainda que 42 professores foram os orientadores das teses. Destes, 95,2\% $(n=40)$ orientaram apenas uma tese enquanto duas professoras foram responsáveis por mais de uma orientação, a saber: Maria Antonia González Cuenca (n=3), Maria del Pilar Fernández-Viader (n=2). Entre esses achados é interessante notar que Maria Antonia González Cuenca figura como autora de uma das primeiras teses defendidas (1993) e também como orientadora em 2004 e 2016, sugerindo uma expertise no campo da educação de surdos na Espanha.

Em relação ao gênero dos autores das teses $(n=45)$, a maioria corresponde o sexo feminino representada por $73,3 \%(n=33)$ do total, enquanto apenas 26,7\% (n=12) são do sexo masculino. No que concerne ao gênero dos orientadores, $69 \%$ (n=29) são homens enquanto $31 \%(n=13)$ são mulheres.

Esses resultados confirmam as assimetrias de gênero na ciência, particularmente quando se trata da atividade de orientação de aluno(as) na pósgraduação em que a participação masculina se sobrepõe à feminina, conforme demonstram estudos em diferentes áreas de conhecimento (KOBAYASHI; RIGOLIN; HAYASHI, 2014; RODRIGUES; GUIMARÃES, 2016). No caso específico da Espanha, de acordo com dados do Instituto Nacional de Estadistica - INE (2018), na última década a porcentagem de mulheres catedráticas tem aumentado gradativamente, no entanto o número de mulheres que conseguem chegar ao mais alto escalão da docência ainda se apresenta baixo em relação ao número de homens. De acordo com Francescutti (2018), um relatório de 2015 da Secretaria de Estado e Investigación, Desarrollo y Innovación informou que no meio acadêmico espanhol as mulheres ocupam apenas $21 \%$ dos cargos, $10 \%$ dos cargos de reitor e $21 \%$ dos cargos gerenciais das instituições de pesquisa; e nas organizações públicas de pesquisa, as mulheres mal chegam a $25 \%$ da categoria mais alta. Essa desigualdade na participação feminina na ciência espanhola está relacionada ao teto de cristal na 
ciência - fenômeno que aponta as barreiras enfrentadas pelas mulheres em aceder a postos de direção em instituições científicas - conforme mencionado por Gallego-Morón e Matús-Lopez (2018).

As teses analisadas foram defendidas em 22 universidades da Espanha, conforme mostram os dados da Figura 2, que apontam a liderança de quatro universidades: Universidad Autónoma de Barcelona $(n=7)$, Universidad de Málaga ( $n=6)$, Universidad de Granada ( $n=5)$ e Unversidad Complutense de Madrid ( $n=4)$. Destaca-se que nas regiões onde essas universidades se localizam existem diversas entidades colaboradoras como a Confederação Nacional de Surdos da Espanha - CNSE e associações de surdos que, por sua vez, formam parcerias com estas universidades a fim de contribuir com pesquisas acadêmicas.

Figura 2 - Distribuição das instituições de defesa das teses

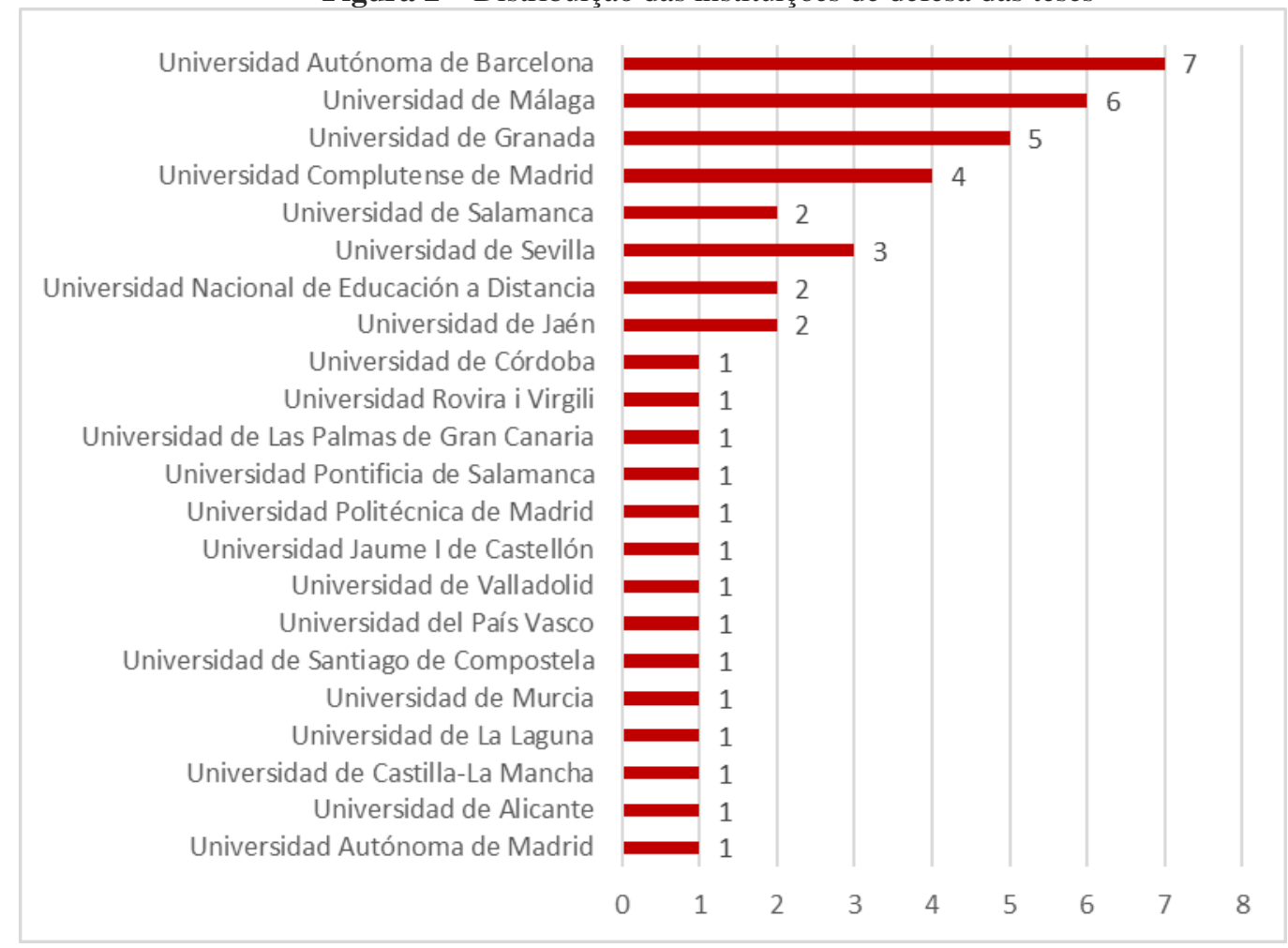

Fonte: Elaboração das autoras.

Nessas 22 universidades há uma diversidade de programas de pósgraduação ( $\mathrm{n}=28)$ nos quais as teses sobre educação de surdos foram defendidas em diferentes áreas ( $\mathrm{n}=5)$, conforme apontam os dados da Tabela 1. 
Tabela 1 - Distribuição das teses doutorais por áreas e programas de pós-graduação

\begin{tabular}{|c|c|c|}
\hline Áreas & Programas de Pós-Graduação & Total \\
\hline \multirow{11}{*}{ Educação } & Educação & 4 \\
\hline & Formação do professorado: prática educativa e comunicação & 4 \\
\hline & Didática das ciências experimentais e da matemática & 2 \\
\hline & $\begin{array}{l}\text { Desenvolvimento curricular, organizativo e profissional } \\
\text { docente: perspectivas didáticas }\end{array}$ & 2 \\
\hline & $\begin{array}{l}\text { Desenvolvimento e educação em contextos formais e não } \\
\text { formais }\end{array}$ & 1 \\
\hline & $\begin{array}{l}\text { Educação infantil e familiar: investigação e intervenção } \\
\text { psicopedagógica }\end{array}$ & 1 \\
\hline & Educação social: fundamentos e metodologia & 1 \\
\hline & Educação e sociedade & 1 \\
\hline & $\begin{array}{l}\text { Gestão e planejamento para a qualidade educativa na } \\
\text { sociedade do séc. XXI }\end{array}$ & 1 \\
\hline & Inovação e investigação em educação & 1 \\
\hline & Investigação sobre processos de atenção à diversidade & 1 \\
\hline \multirow{8}{*}{ Psicologia } & Psicologia & 9 \\
\hline & Psicologia clínica e da personalidade & 1 \\
\hline & Aprendizagem, diversidade e escola & 1 \\
\hline & Ciência cognitiva e linguagem & 1 \\
\hline & Intervenção em saúde mental & 1 \\
\hline & Intervenção psicológica em âmbitos educativos & 1 \\
\hline & Intervenção psicossocial & 1 \\
\hline & Investigação e intervenção em Psicologia & 1 \\
\hline \multirow{6}{*}{ Linguística } & Intervenção na linguagem & 2 \\
\hline & Comunicação, linguagem e patologia & 1 \\
\hline & Didática da língua e da literatura & 1 \\
\hline & Estudos avançados em tradução e interpretação & 1 \\
\hline & Estudos de tradução e interpretação & 1 \\
\hline & Linguística & 1 \\
\hline \multirow{2}{*}{ Saúde } & Saúde Pública & 1 \\
\hline & Enfermagem e Fisioterapia & 1 \\
\hline Engenharia & Engenharia e Telecomunicações & 1 \\
\hline \multicolumn{2}{|c|}{ TOTAL } & 45 \\
\hline
\end{tabular}

Fonte: Elaboração das autoras

Nota-se na Tabela 1 a forte presença dos programas de pós-graduação $(n=11)$ da área de Educação nos quais foram defendidas 42,2\% (n=19) das teses e da área de Psicologia $(n=8)$, com 35,6\% $(n=16)$ das teses. Na sequência, comparece os programas de pós-graduação da área de Linguística (n=6) com $15,6 \%$ do total de teses A minoria das teses doutorais representando 6,6\% $(n=3)$ foram defendidas em programas das áreas de Saúde $(n=2)$ e Engenharia $(n=1)$. Esses achados demonstram que para além do campo da Educação, os estudos sobre educação de surdos recebem relevantes contribuições das áreas da Psicologia e da Linguística mediante aportes teóricos que colaboram para o 
melhor entendimento de questões relacionadas, por exemplo, às intervenções psicológicas com alunos surdos em ambientes educativos e às práticas pedagógicas para aquisição de linguagem e letramento dessa população.

A Figura 3 apresenta a das temáticas mais abordadas nas teses, isto é, aquelas que foram citadas mais de duas vezes pelos autores ao atribuírem as palavras-chave de seus estudos.

Figura 3 - Distribuição das temáticas abordadas nas teses

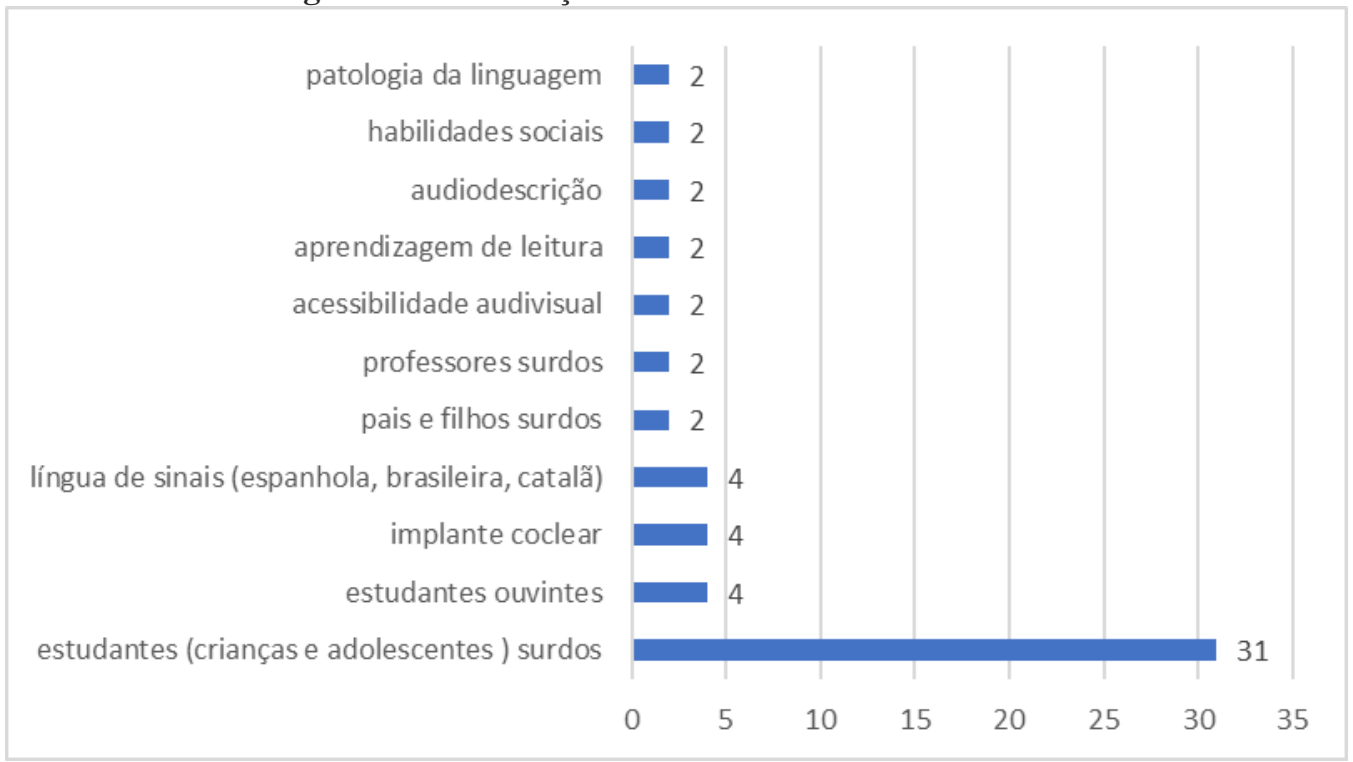

Fonte: Elaboração das autoras.

Na Figura 3 observa-se as temáticas mais frequentes sobre educação de surdos associadas às palavras-chaves atribuídas pelos autores e presentes nas teses doutorais, as quais estão relacionadas: a) à população alvo dos estudos $(n=39)$, a saber: estudantes (crianças e adolescentes) surdos e ouvintes, pais e filhos surdos e professores surdos; b) às influências teóricas de diferentes áreas de conhecimento, tais como a Linguística Aplicada ("patologia da linguagem"); e Psicologia ("habilidades sociais"); c) a estudos que abordam as biotecnologias e tecnologias assistivas, tais como o "implante coclear" $(n=4)$, a "audiodescrição" (n=2) e que promovem a inclusão de pessoas surdas em ambientes escolares, profissionais e na vida cotidiana. Também foi identificado um expressivo conjunto de palavras-chave $(n=78)$ atribuídas apenas uma vez pelos autores, demonstrando que há uma dispersão de temáticas sobre a educação de surdos abordadas nas teses doutorais espanholas. 
Para um maior aprofundamento sobre a educação de surdos abordada nas teses investigadas $(n=45)$ foi realizada a leitura das teses integrais disponibilizadas em domínios públicos $(n=26)$ visando identificar as principais abordagens comunicativas descritas como predominante nos estudos, de acordo com a posição linguística adotada pelos autores dessas teses.

Ressalta-se que embora os termos abordagem e metodologia nomeiem princípios conceituais distintos na área da linguística aplicada, como aponta Borges (2010), diversas vezes esses termos são usados como sinônimos, em especial quando se trata da educação de pessoas surdas. Desse modo, fez-se a opção pela utilização da expressão abordagem, em referência à filosofia que orienta os processos de ensino e aprendizagem da linguagem para surdos.

A Figura 4 exibe as principais abordagens comunicativas de exposição à linguagem e sua relação com a aprendizagem na educação de surdos que emergiram dos estudos analisados.

Figura 4 - Principais abordagens comunicativas das teses doutorais

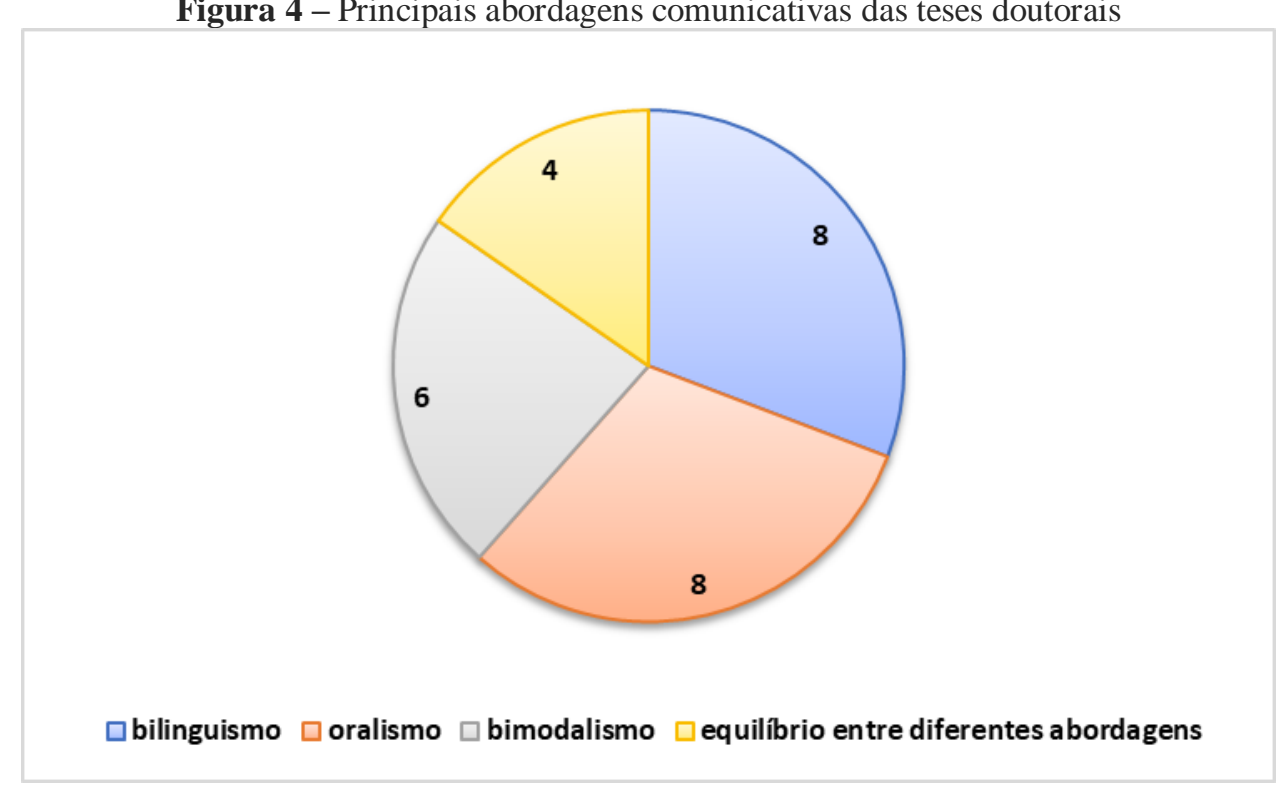

Fonte: Elaboração das autoras.

As abordagens predominantes do bilinguismo $(n=8)$ e oralismo $(n=8)$ reuniu 61,4\% das teses. Na educação de surdos, segundo Lacerda (1998) o bilinguismo consiste na ideia de que a língua de sinais é a língua natural dos surdos, que, mesmo sem ouvir, podem desenvolver plenamente uma língua 
visogestual. De acordo com essa visão a língua de sinais é encarada como língua materna do surdo e a língua oral/escrita como sua segunda língua.

No tocante à abordagem do bilinguismo esta foi representada por 30,7\% dos trabalhos $(n=8)$ entre os quais foram identificados $11,5 \% \quad(n=3)$ que se referiram à abordagem do bilinguismo e da biculturalidade, isto é, a vertente de que os "surdos são sujeitos biculturais que guardam uma cultura própria, representativa da comunidade surda, cuja diferença linguística é expressa pelo canal visuoespacial" (RIBEIRO; SILVA, 2017, p. 1). Ou seja, essa abordagem, baseia-se no entendimento da circulação do sujeito surdo entre as culturas surda e ouvinte na medida em que este convive com duas línguas e culturas: a língua gestual e cultura da comunidade surda do seu país e a língua oral e cultura ouvinte de seu país.

A abordagem do oralismo foi identificada em 30,7\% ( $n=8)$ das teses doutorais. $\mathrm{O}$ oralismo enquadra-se no modelo clínico que destaca a importância da integração do surdo na comunidade de ouvintes por meio da reabilitação da fala proibindo a utilização da língua de sinais e transformando as estratégias pedagógicas em terapêuticas. Embora essa perspectiva vise integrar os surdos na comunidade de ouvintes, o oralismo caminha na direção de uma normalização exigida pela sociedade, conforme assinalam Bentes e Hayashi (2016).

Por sua vez, a abordagem do bimodalismo esteve presente em 23,1\% (n=6) das teses. Consiste na utilização simultânea das duas línguas: a oralauditiva e a gestual-visual, em que os códigos manuais obedecem à organização estrutural da língua oral. Tais sinais normalmente são extraídos das línguas de sinais da comunidade surda do país que a utiliza. A "comunicação bimodal" refere-se, portanto, a uma estratégia comunicativa e não a um conjunto fixo de sinais ou uma metodologia própria de complementação que varia de acordo com as características da criança (MONFORT, 2006).

Finalmente, foram identificados em $15,4 \%(n=4)$ das teses um equilíbrio entre diferentes abordagens comunicativas, ou seja, a perspectiva de oferecer aos alunos surdos as possibilidades de comunicação existentes e adequadas à sua peculiaridade linguística, considerando que a opção por uma ou outra modalidade comunicativa, dependerá entre outros fatores, da concepção educativa da família, dos recursos disponíveis e das necessidades educativas 
concretas de cada aluno. Dessa forma e, perpassado pelas pesquisas anunciadas, os agentes escolares envolvidos no processo de escolarização da criança surda juntamente com a comunidade escolar e a família da criança, devem priorizar os sistemas que melhor contribuam para o seu desenvolvimento cognitivo e linguístico, assim como com o desenvolvimento fonológico e estrutural da modalidade comunicativa escolhida. Sendo assim, expressa a ideia de que os profissionais que atuam no âmbito educacional em especial, não devem assumir uma posição apriorística radical de prescrição de uma modalidade e proscrição de outra. Eles devem considerar as reais e efetivas necessidades e condições da criança surda acerca dos impactos reativos e complementares da língua oral e da língua de sinais para o desenvolvimento cognitivo, linguístico e acadêmico da criança.

Os resultados das pesquisas analisadas permitem apontar a preferência dos diversos atores escolares pelo desenvolvimento da linguagem oral pelos alunos surdos em comparação com a língua de sinais e o bilinguismo, no entanto, sempre respeitando o ritmo e condições apresentadas pelos sujeitos surdos. Aponta-se ainda o método bimodal também como prioridade comunicativa para alguns profissionais que trabalham com alunos surdos, em especial os professores de Audição e Linguagem que atuam de forma direta com o aspecto linguístico desses alunos nos centros escolares.

\section{Considerações finais}

Os resultados do panorama bibliométrico apresentado nesta pesquisa apontam para uma diversificada produção científica sobre educação de surdos oriunda de teses de doutorado defendidos em universidades espanholas. Partindo dessa diversidade, torna-se importante destacar as realidades legislativa e financeira que perpassam as questões que envolvem a escolarização de alunos surdos e os apoios e recursos oferecidos para o ensino desse alunado no contexto espanhol. Tais elementos subsidiam e incidem diretamente no desenvolvimento do aluno surdo e nas práticas a serem adotadas pelos centros educativos e pelos professores, uma vez que eles se encontram como prioridade na normativa do país. Sendo assim, tais elementos influenciam os dados coletados nas pesquisas da referida área e, por conseguinte, nos resultados das análises destas produções. 


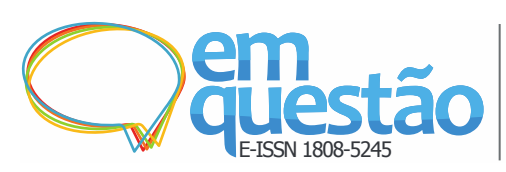

Educação de surdos na Espanha análise bibliométrica em bases de dados de teses doutorais

Daiane Natalia Schiavon e Maria Cristina Piumbato Innocentini Hayashi

Em relação à vinculação institucional das teses evidencia-se a liderança de três universidades: Barcelona, Málaga, Granada e a Complutense de Madrid, sendo esta última uma das universidades mais prestigiadas da Espanha e com forte tradição na formação de professores e ensino para a diversidade.

Sobre a distribuição das teses por área de conhecimento, os resultados expressaram a forte presença das áreas de Psicologia e Educação demonstrando a supremacia das áreas de Ciências Humanas nos estudos sobre educação de surdos. Acerca da distribuição das teses segundo as temáticas abordadas, extraídas das palavras-chave atribuídas pelos autores, observa-se que as temáticas ligadas à área da "Educação" englobaram "estudantes surdos", "educação de surdos", "professoras surdas" e "estudantes ouvintes". Um número expressivo também foi encontrado na temática relacionada à área da Comunicação, envolvendo as abordagens comunicativas utilizadas com estes alunos surdos, além da área da Saúde e de um total expressivo de diferentes temáticas em outras áreas do conhecimento.

Conforme já mencionado, a maioria das teses estavam disponíveis na íntegra e ao analisar seus conteúdos notou-se uma forte preocupação com a problematização de questões relacionadas a apoios e recursos para a aprendizagem, comunicação e linguagem, e práticas pedagógicas voltadas para a educação de alunos surdos. Em contrapartida ressalta-se a baixa ocorrência de estudos nas seguintes áreas: comunicação com surdos implantados, história da educação de surdos, legenda em língua de sinais, mercado de trabalho e matemática para surdos.

Em relação às modalidades comunicativas, atualmente o debate principal está entre a língua oral e o bilinguismo, e ainda considerando os diferentes sistemas complementares que apoiam a comunicação como, por exemplo, o bimodalismo e a palavra complementada. Em visto disso, deve-se levar em conta que a escola e os profissionais devem se adaptar ao aluno surdo e não visar impor um sistema de comunicação ou outro porque é o que está "na moda" e sim, considerar suas características, necessidades e possibilidades de cada um, conduzindo assim os envolvidos ao sistema mais adequado de comunicação. Assim, o debate sobre a educação de surdos deve ser pautado em qual o método 
comunicativo mais apropriado para cada caso e quais devem ser os elementos mais adequados para a educação de "tal" aluno surdo.

Embora os achados da investigação tenham identificado um total ainda pequeno de teses espanholas sobre educação de surdos defendidas no período entre 1987 e 2017, a temática pesquisada teve crescimento expressivo na segunda década do século XXI sinalizando que esse crescimento pode continuar diante do avanço das normativas do Estado espanhol para a educação de surdos. Tais avanços na produção científica analisada revelam a preocupação dos diversos profissionais envolvidos no processo de escolarização de alunos surdos em busca de um ensino de melhor qualidade.

Destarte, para futuros estudos sobre a produção científica de educação de surdos sugere-se a utilização de outras bases de dados internacionais e diferentes tipologias documentais, tais como artigos científicos. Isso permitirá comparar resultados e fortalecer as análises sobre o conhecimento científico produzido, de modo a oferecer subsídios aos pesquisadores, revelando avanços e lacunas existentes, a fim de contribuir para o aprimoramento do campo de estudos sobre educação de surdos e para uma prática pedagógica cada vez mais inclusiva.

\section{Financiamento}

Coordenação de Aperfeiçoamento de Pessoal de Nível Superior (CAPES) Programa Nacional de Pós Doutorado (PNPD).

\section{Agradecimentos}

Aos pareceristas que contribuíram com sugestões relevantes para o aperfeiçoamento desse texto.

\section{Referências}

ALBRES, N. A. de; LACERDA, C. B. F. de. Interpretação educacional como campo de pesquisa: estudo bibliométrico de publicações internacionais e suas marcas no campo nacional. Cadernos de Tradução, Florianópolis, v. 1, n. 31, p. 179-204, 2013.

ARIK, E. Sign language research in Web of Science. Journal of Scientometric Research, New Delhi, v. 3, n. 3, p. 143-149, 2014. 
BENTES, J. A. de O.; HAYASHI, M. C. P. I. Normalidade, diversidade e alteridade na história do Instituto Nacional de Surdos. Revista Brasileira de Educação, Rio de Janeiro, v. 21, n. 67, p. 851-874, dez. 2016.

BORGES, E. F. V. Metodologia, abordagem e pedagogias de ensino de língua(s). Linguagem \& Ensino, Pelotas, v. 13, n. 2, p. 397-414, 2010.

CNSE, Confederación Estatal de Personas Sordas. La Fundación CNSE para la superación de las barreras de comunicación. 2015.

ESPAÑA. Ministerio de Educación, Cultura y Deporte. El Sistema Educativo Español. Madrid: MECD/CIDE, 2008.

ESPAÑA. Ministerio de Educación, Cultura y Deporte. Ley Orgánica de Educación 2013 (LOE). Boletín Oficial del Estado, Madrid, n. 295, 2013.

ESPAÑA. Ministerio de Educación, Cultura y Deporte. Ley Orgánica 8/2013 para la Mejora de la Calidad Educativa. (LOMCE). Boletín Oficial del Estado, Madrid, 2013.

ESPAÑA. Ministerio de Educación, Cultura y Deporte. TESEO: Base de datos de Tesis Doctorales de las Universidades españolas, 2018.

ESPAÑA. Ministerio de la Presidencia. Ley 27/2007, de 23 de octubre, por la que se reconocen las lenguas de signos españolas y se regulan los medios de apoyo a la comunicación oral de las personas sordas, con discapacidad auditiva y sordociegas, 2007.

ESPAÑA. Ministerio de la Presidencia. Real Decreto 334/1985, de 6 de marzo de 1985 de Ordenación de la Educación Especial, 1985.

FERNÁNDEZ-CANO, A.; TORRALBO, M.; VALLEJO, M. Time series scientific growth in Spain doctoral theses (1848-2009). Scientometrics, Hoboken, v. 91, p. 15-36, 2012.

FRANCESCUTTI, P. La visibilidad de las científicas españolas. Barcelona: Fundación Dr. Antoni Esteve, 2018. (Cuadernos, 44)

GALLEGO-MORÓN, N.; MATUS-LÓPEZ, M. Techo de cristal en las universidades españolas: diagnóstico y causas. Profesorado: Revista de Currículum y Formación del Profesorado, Granada, v. 22, n. 3, p. 209-229, sept. 2018.

GASCÓN, A.; STORCH, J. G. Historia de la Educación de sordos en España. Madrid: Editorial Universitaria Ramón Areces, 2004.

GONZÁLEZ PÉREZ, T. Itinerario de la Educación Especial en el sistema educativo. de la Ley Moyano a la Ley General de Educación. In: BERRUEZO, 
M.R. (Org.). El largo camino hacia una educación inclusiva: la educación especial y social del siglo XIX a nuestros días. Pamplona, 2009, p. 249-260.

JANIS, I. O problema da validação da análise de conteúdo. In: LASSWELL, Harold; KAPLAN, Abraham. A linguagem da política. Brasília: Editora UnB, 1982.

KING, C. M. Research productivity in the education of hearing impaired individuals. Journal of Special Education, v. 23, n. 3, p. 279-293, 1989.

KOBAYASHI, E.; RIGOLIN, C. C. D.; HAYASHI, M. C. P. I. Lideranças femininas nos Institutos Nacionais de Ciência e Tecnologia (INCTs): indicadores cientométricos e biografias. In: SEMINÁRIO NACIONAL DE CIÊNCIA E TECNOLOGIA, 14, 2014, Belo Horizonte. Anais [...] Belo Horizonte, 2014. p. 1-15.

LACERDA, C. B. F. de. Um pouco da história das diferentes abordagens na educação dos surdos. Cadernos CEDES, Campinas, v. 19, n. 46, p. 68-80, set. 1998.

MINAYO, M. C. S.; SANCHES, O. Quantitativo-qualitativo: oposição ou complementaridade? Cadernos de Saúde Pública, Rio de Janeiro, v. 9, n. 3, p. 239-262, jul./set. 1993.

MONFORT, M. La práctica de la comunicación bimodal. Madrid:Enthaediciones, 2006.

ONCE, Organización Nacional de Ciegos Españoles. Un proyecto histórico de emancipación personal e integración social de los ciegos y deficientes visuales en España. 2015. RAMOS, D. M.; HAYASHI, M. C. P. I. O lugar da educação de surdos nas dissertações e teses. Revista Brasileira de Educação Especial, Marília, v. 24, n. 2, p. 247-260, 2018.

RIBEIRO, C. B.; SILVA, D. N. H. Trajetórias escolares de surdos: entre práticas pedagógicas e processos de desenvolvimento bicultural. Psicologia: Teoria e Pesquisa, Brasília, v. 33, e3339, 2017.

RODRIGUES, J. G.; GUIMARÃES, M. C. S. A Fundação Oswaldo Cruz e a ciência no feminino: a participação feminina na prática e na gestão da pesquisa em uma instituição de ensino e pesquisa. Cadernos Pagu, Campinas, v. 46, p. 197-222, abr. 2016.

SÁNCHEZ JIMÉNEZ, R.; BLÁZQUEZ ORLANDO, M.; MONTESI, M.; BOTEZAN, I. La producción de tesis doctorales en España (1995-2014): evolución, disciplinas, principales actores y comparación con la producción científica en WoS e Scopus. Revista Española de Documentación Científica, Madrid, v. 40, n. 4, e188, oct.-dic. 2017. 
SANTOS, S.A.; OLIVEIRA, M. A produção científica sobre Língua Brasileira de Sinais (Libras) presente nos currículos Lattes do CNPq. Perspectivas em Ciência da Informação, Belo Horizonte, v. 22, n. 4, p. 35-46, dez. 2017.

SANZ-CASADO, E.; DE FILIPPO, D.; GARCÍA ZORITA, C.; EFRAÍNGARCÍA, P. Observatório IUNE: una nueva ferramienta para el seguimiento de la actividad investigadora del sistema universitário español. Bordón: Revista de Pedagogía, Madrid, v. 63, n. 2, p. 101-115, 2011.

SCHIAVON, D. N.; HEREDERO, E. S. Sistema educativo espanhol: o apoio de professores especialistas e reflexões para o contexto brasileiro. Interfaces da Educação, Parnaíba, v. 9, n. 25, p. 404-422, 2018.

SCHIAVON, D. N. Inclusão de alunos surdos em Castilla-La Mancha (Espanha): reflexões para o contexto brasileiro. 2017. Tese (Doutorado em Educação Escolar) - Faculdade de Ciências e Letras (Campus Araraquara), Universidade Estadual Paulista "Júlio de Mesquita Filho", Araraquara, 2017.

SILVA, M. R.; HAYASHI, C. R. M.; HAYASHI, M. C. P. I. Análise bibliométrica e cientométrica: desafios para especialistas que atuam no campo. InCID: Revista de Ciência da Informação e Documentação, Ribeirão Preto, v. 2, n. 1, p. 110-129, jan./jun. 2011.

SILVA, R. A. da; SANTOS, R. N. M. dos; RODRIGUES, R. S. Estudo bibliométrico da base LISA: um enfoque nos artigos sobre os surdos. Em Questão, Porto Alegre, v. 17, n. 1, p. 289-304, jan./jun. 2011.

TDR. Tesis Doctorales en Rede. 2018. Disponível em: https://www.tesisenred.net/ Acesso em: 11 março. de 2018

TIANA FERRER, A. Espanha: Inflexões nas políticas de qualidade educativa. In: BRASIL. Ministério da Educação. Educação e conhecimento: a experiência dos que avançaram. Brasília: Unesco, 2004. p. 293-331.

VAN RAAN, A. F. J. Measuring science. In: MOED, H. F.; GLÄNZEL, W.; SCHMOCH, U. (Eds.). Handbook of quantitative science and technology research. Dordrecht: Kluwer Academic Publishers, 2004. p. 19-50.

\title{
Scientific production on the subject of Deaf Education in the Spanish context: a bibliometric analysis
}

\begin{abstract}
The education of deaf students is a theme present in academic debates, being reflected in studies in the scenario of national and international scientific production. The aim of the present work is to identify and analyze the Spanish scientific production from doctoral theses on the education of the deaf and to present bibliometric indicators that best represent the profile of the
\end{abstract}


themes of these researches. From a bibliometric approach combined with the content analysis, the study chose to select the Theses Database and Doctoral Thesis Network, both from the Ministry of Education, Culture and Sport of the Government of Spain, through the use of the following search terms "deaf" and "hearing impaired". The following categories were analyzed in the selected corpus $(n=45)$ : temporal evolution, authors, supervisors and their respective genres, defense institutions, areas of knowledge, themes and communicative approaches used in the studies. The results of this bibliometric panorama express a diverse scientific production on the education of the deaf in doctoral programs $(n=28)$ in Spanish universities $(n=22)$ on different topics, including those related to the target population of the studies and the assistive biotechnologies, with preponderance of studies in the areas of Education, Psychology and Linguistics. It was verified that among the communicative approaches adopted in the studies preponderated oralism and bilingualism. In the conclusions it is recommended that future studies use different databases and documentary typologies, such as scientific articles, aiming to establish comparisons and to broaden the analyzes on the scientific production of deaf education.

Keywords: Education of the deaf. Spain. Scientific production. Bibliometria.

Recebido: 21/01/2019

Aceito: 28/03/2019 